\title{
Oscillation damping in the powertrain unit of transport vehicles
}

\author{
Alexander Taratorkin ${ }^{1, *}$, Viktor Derzhanskii ${ }^{1,2}$, and Igor Taratorkin ${ }^{1}$ \\ ${ }^{1}$ IES UB RAS, Department of Transportation Vehicles Mechanics, 620049, Ekaterinburg, Russian Federation \\ ${ }^{2}$ Kurgan State University, Department of Applied Mechanics, 640020, Kurgan, Russian Federation
}

\begin{abstract}
The paper presents the results of an analytical experimental research of conditions for excitation of oscillatory processes in steady-state conditions and in the process of starting-up an engine equipped with a modern Common Rail fuel supply control system. Based on the results of mathematical simulation, the dependence of the dynamic torque amplitude on boosting acceleration during engine start-up and on the parameters of the elastic-dissipative coupling (connection) of the engine with the transmission is analyzed. It establishes the rationale for a possibility of optimizing the fuel supply system control algorithms for a modern diesel engine, taking into consideration the dependence of the process on the properties of the transmission and the peculiarities of its operation.
\end{abstract}

\section{Introduction}

Dynamic loading of powertrain units (PTU) of transport vehicles at steady-state operating modes is determined by resonant oscillations excited by the harmonic components of the engine torque when disturbance frequencies coincide with Eigen frequencies of the mechanical system. It should be noted that nowadays numerous methods for their damping have been developed by introducing damping elements, synthesizing low-frequency oscillation filters [1-4], and installing a dynamic pendulum vibration absorber [510]. Taking resonant oscillations outside the operating range of engine shaft speeds can be provided by selecting the stiffness $\mathrm{C}$ or the moment of inertia $J_{\text {пр. In }}$ power unit of many transport vehicles with hydromechanical transmission (HMT), with torque convertor (TC) cast wheels, the function of the elastic element torsional oscillation damper - is performed by a torsion shaft. The torsion shaft is installed between the engine flywheel and the torque converter pumping wheel. This solution allows increasing the specific volumetric efficiency of the engine-transmission compartment in comparison with foreign designs. However, taking resonance oscillations outside the limits of the engine operating range does not exclude their excitation at low frequencies - when the engine starts-up and stalls [11]. Considering the high energy consumption of the process, a problem arises to ensure strength of the elastic element, i.e. the torsion shaft. In Russia, calculation studies of torsional oscillations in transport vehicle transmissions began in the 50-60 s of the last century. For the basis, the works of V.P. Terskikh [12], S.E. Burtsev [13], V.L. Veits, A.E. Kochura [14], A.I. Grishkevich [5], et al were accepted. These works were the foundation for development of a method for calculating stationary torsional oscillations excited by an internal combustion engine. Scientific works of V.A. Zaitsev, M.G. Zhuchkov et al. are devoted to the problems of research, estimation and reduction of dynamic loading, ensuring the durability of torsion shafts for vehicles with traditional engines, and design engineering of torsional oscillation dampers for transport vehicle transmissions.

The effect of excitation of resonance oscillations is especially acute at starts-up of the engine with modern intelligent mechatronic fuel control systems (Common Rail). Creation of perspective powertrain units requires development of new control algorithms and their software implementation.

In accordance with the abovementioned, the subject of the research is PTU comprising a HMT and a diesel engine with an intelligent mechatronic Common Rail fuel control system.

The objective of the work is to study the process of dynamic loading of the PTU elements at engine start-up and development of recommendations for its reduction.

To evaluate and analyze the dynamic loads in the engine start-up mode, it is essential to create a model that takes into account an actual state, the properties of the system elements, including nonlinearity of the oscillation damper elastic-dissipative characteristics. Taking into consideration ambiguity of the parameters at numerical simulation of a starts-up process, it is necessary to apply a large number of assumptions. In this connection, the time functions of the kinematic and power parameters are determined experimentally by the diagnostic codes of the CAN-bus of the information, measuring and control system of the engine management. Fig. 1, 2 show the nature of changes of the parameters of the engine equipped with the specified system: rotary speed of the shaft, its calculated torque, injected fuel quantity and angle of the main injection event.

*Corresponding author: alexandr.taratorkin@mail.ru 


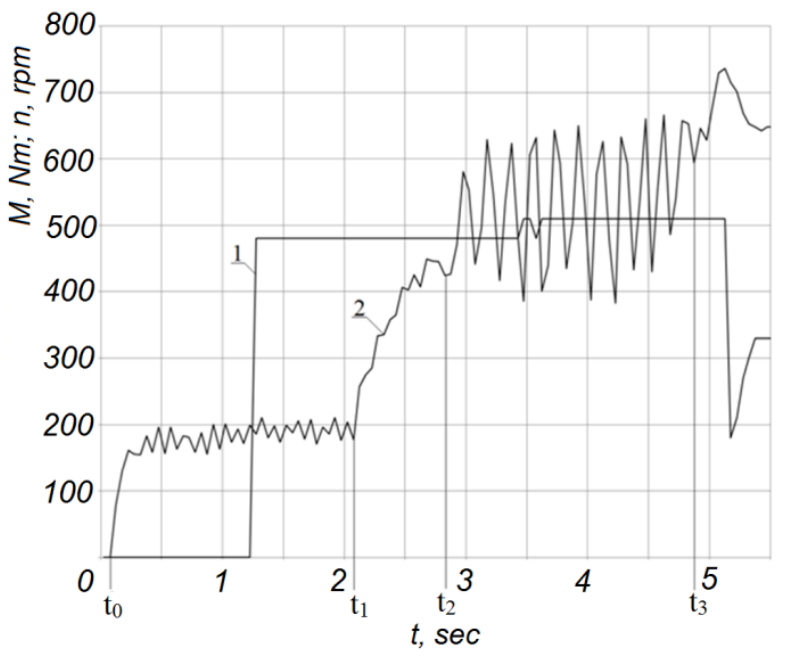

Fig. 1. Fragment of the oscillogram with measured acting torque (1) and crankshaft speed (2) in start-up and idle modes.

Between 0 and $t_{1}$ (Fig. 1) the starter rotates the engine shaft until it reaches the starting frequency $(18 \ldots$ $22 \mathrm{rad} / \mathrm{s})$ without fuel supply. After that $\left(t_{1} \leq t<t_{2}\right)$ the fuel supply for the engine is activated and during $0,7 \ldots$ $0,8 \mathrm{sec}$ intensive increase of the engine angular velocity occurs. Further, when the third engine order coincides with Eigen frequency of the system resonant oscillations of the engine shaft are excited at a frequency of $26 \ldots 28$ $\mathrm{Hz}$. This leads to a slower acceleration of engine. Should be noticed that the speed sensor sample rate according to SAE J1939-71 protocol is $20 \mathrm{~Hz}$. However, required minimum sample rate frequency in accordance with the Kotelnikov theorem is around $60 \mathrm{~Hz}$ [17]. Due to this fact, the oscillations in Figs. 1 and 2 can be considered as a qualitative illustration only. For precise determination of the Eigen frequency the oscillations of the shaft were measured with normal inductive sensor.

With help of high sample rate irregularity of rotation of the crankshaft was successfully detected. Usage of the cyclic functions of the application software [18, 19] provided determination of the order components of the process. In this case, it was identified resonant due to coincidence of Eigen frequency with third engine order. The described process lasts for $1.5 \ldots 2.0 \mathrm{~s}$ until point $t_{3}$. With this, powerful dynamic torque oscillations with amplitude $\quad M_{\text {dyn }}=J_{\text {reduced }} A \dot{\omega}^{2}$ (for $\left.\varphi=6 \ldots 7 \mathrm{deg} M_{\mathrm{dyn}}=3 \ldots 4 \mathrm{kNm}\right) \quad$ supplements stationary torque which leads to rotational oscillations $1500 \ldots 3000 \mathrm{rad} / \mathrm{sec}^{2}$.

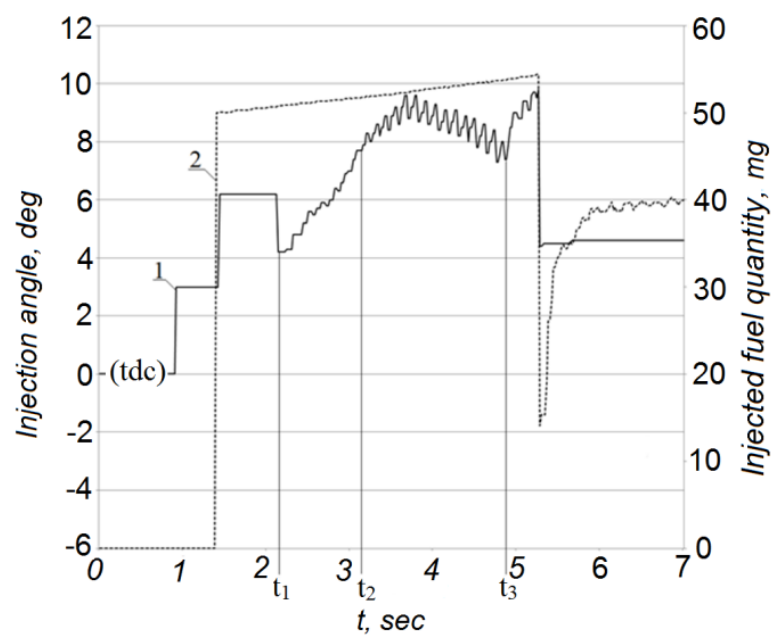

Fig. 2. Fragment of the oscillogram with recorded angle of the main injection event (1) and injected fuel quantity (2) in startup and idle modes.

During oscillations injection rate remains unchanged (Fig. 2) and it is insufficient to continue the engine boost. Due to an increase in the required level of energy consumption, the average value of the engine shaft speed in this mode does not increase quickly enough (the acceleration of passing through the resonant zone does not exceed $8,5 \mathrm{rad} / \mathrm{s}^{2}$.) After the rotary speed exceeds of the resonant zone, its value increases dramatically and reaches the value of idle run $(\mathrm{n}=750 \mathrm{rpm})$. Due to instability of the engine shaft speed, the fuel supply system operation algorithm is disturbed. In this case, with a phase displacement, the system regulates the injection angle and injection fuel quantity, which further destabilizes the process. Later, the injection fuel quantity will be stabilized at the level corresponding to the idle mode.

Excitation of energy-consuming torsion shaft resonance oscillations during start-up of the engine with a modern intelligent mechatronic system prolongs the start-up process as a result of electronic system hangan occurrence of the so-called "data collision" [20]. In this case, accumulation of the number of mechanical system loading cycles in the resonance mode occurs, including torsion shaft. This mode is an off-design mode and leads to torsion destruction. In work [11], the process of classic diesel engine start-up (with a traditional fuel feed system) was studied in detail. The author established a dependence of the maximum torsion shaft dynamic loads on the acceleration of passing through the resonance. As follows from the author's findings, when increasing the acceleration of passing through the resonance zone, the level of maximum dynamic loads on the torsion shaft is reduced by $10 \ldots$ $20 \%$ compared to the stationary mode of resonant oscillations (with the system natural frequency coinciding with the third harmonics of the diesel). In this case, the range from 50 to $200 \mathrm{rad} / \mathrm{s}^{2}$ is investigated. In the case under consideration, the acceleration of passing the resonance zone lies in the range from 6 to $8.5 \mathrm{rad} / \mathrm{s}^{2}$, i.e. the start-up occurs under extremely unfavourable 
conditions (in the time interval from $t_{2}$ to $\left.t_{3}\right)$ ) and the mechanical system is, actually, in the state of resonance in the steady-state mode. It should be noted that the level of implemented resonance loads depends significantly on mechanical system acceleration and varies within a wide range, determined by the engine thermal condition, by start-up technique (by an electric starter or by a pneumatic system).

\section{Computational scheme and simulation model}

The findings make it possible to develop a mathematical model for analyzing possibilities of reducing the torsion shaft dynamic loading. The computational scheme is presented in the form of two inertia masses - of the flywheel with the moment of inertia $J_{d}$ and the moment of inertia of the pump impeller with the moment of inertia $J_{n}$, connected with each other by elasticdissipative nonlinear coupling with stiffness $\mathrm{C}=29$ $\mathrm{kNm} / \mathrm{rad}$ and by the torque of pretension $\mathrm{M}_{\mathrm{tpt}}=$ $0.35 \mathrm{kNm}$ and by the torque of friction $\mathrm{M}_{\text {fric }}=$ $0.33 \mathrm{kNm}$. The motion of a two-mass system is described by second-order differential equations:

$$
\begin{gathered}
J_{f l w l} \ddot{\varphi}+M(\varphi, \dot{\varphi})=M_{d} \\
J_{p m p} \ddot{\varphi}-M(\varphi, \dot{\varphi})=0
\end{gathered}
$$

where $M(\varphi, \dot{\varphi})$ is an elastic torque, which is the function of the angle of the shaft twist $\varphi$ and of the relative displacement speed $\dot{\varphi}$, taking into account the phenomenon of non-linearized "dry" friction of the oscillation damper; $M_{d}$ is a polyharmonic engine disturbance torque. The simulation model, performed in the LMS Amesim package [21], is shown in Fig. 3.

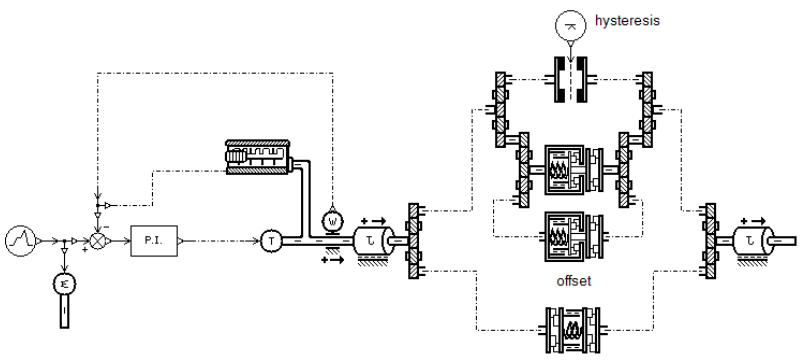

Fig. 3. Simulation model of the dynamic system for researching the process of engine starting-up.

The model comprises the control shaping unit (allows for setting engine boosting acceleration during start-up), the engine unit as a source of a disturbance torque that allows for specifying periodic and constant components; the torsional oscillation damper unit and the inertial masses of the dynamical system proper.

\section{Results of simulation}

The simulation results for various boosting acceleration algorithms in the start-up process are shown in Table 1 and are shown in Fig. 4.
Table 1. Results of mechanical system dynamic load simulationat engine start-up.

\begin{tabular}{|c|c|c|c|c|}
\hline$\#$ & $\begin{array}{c}\text { Dynamic system } \\
\text { parameters }\end{array}$ & \multicolumn{3}{|c|}{ Torque amplitude, $\mathrm{kNm}$} \\
\hline 1 & $\begin{array}{c}\text { Rotary } \\
\text { acceleration at } \\
\text { starting } \dot{\omega}, \mathrm{rad} / \mathrm{s}^{2}\end{array}$ & 6 & 50 & 100 \\
\hline \multirow{2}{*}{2} & $\begin{array}{c}\text { Stiffness } \mathrm{C}=29, \\
\mathrm{kNm} / \mathrm{rad} \\
\text { Parameters of the } \\
\text { hysteresis loop } \\
M_{\text {fric }}=0, M_{t p t}= \\
0\end{array}$ & 3.0 & 2.5 & 2.0 \\
\hline & $\begin{array}{c}\text { Stiffness } \mathrm{C}=29, \\
\mathrm{kNm} / \mathrm{rad} \\
\text { Parameters of the } \\
\text { hysteresis loop } \\
M_{\text {fric }}= \\
0.35 \mathrm{kNm}, M_{t p t} \\
0.33 \mathrm{kNm}\end{array}$ & 1.2 & 0.9 & 0.8 \\
& & & \\
\hline
\end{tabular}

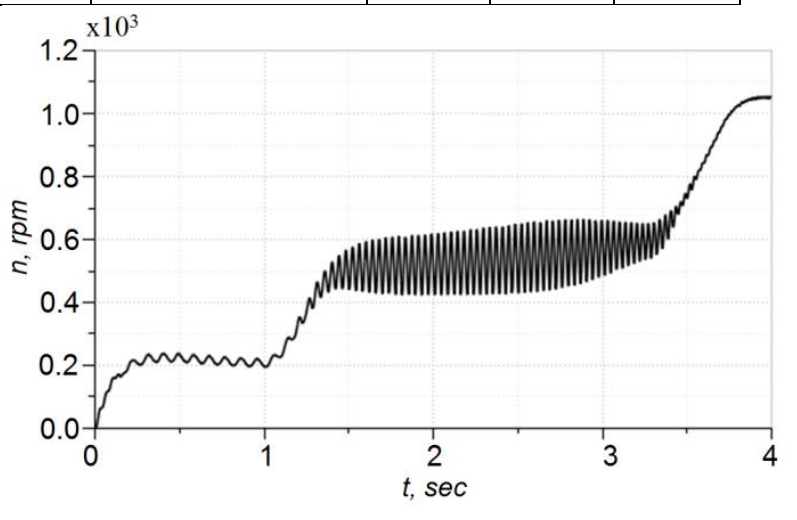

a





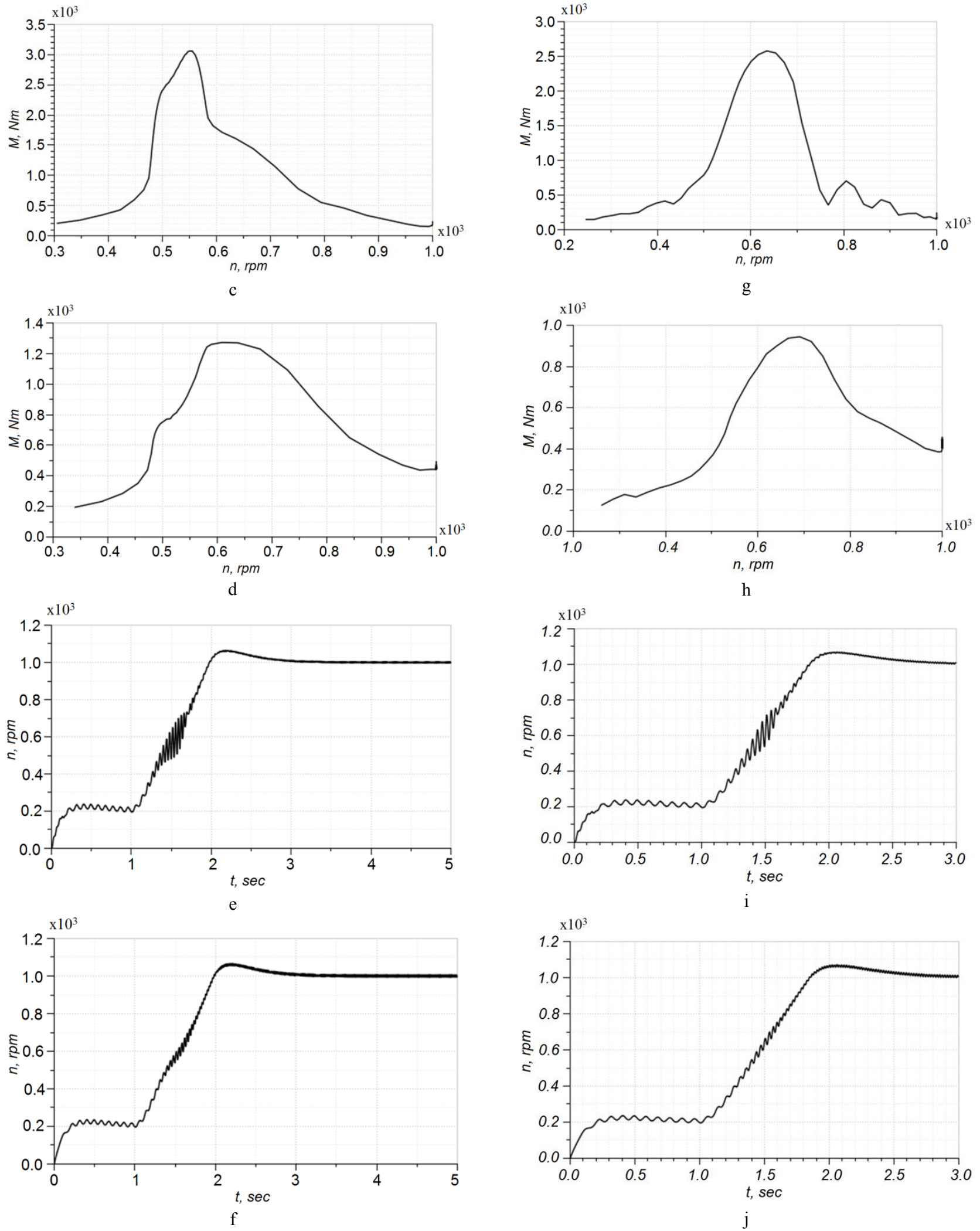


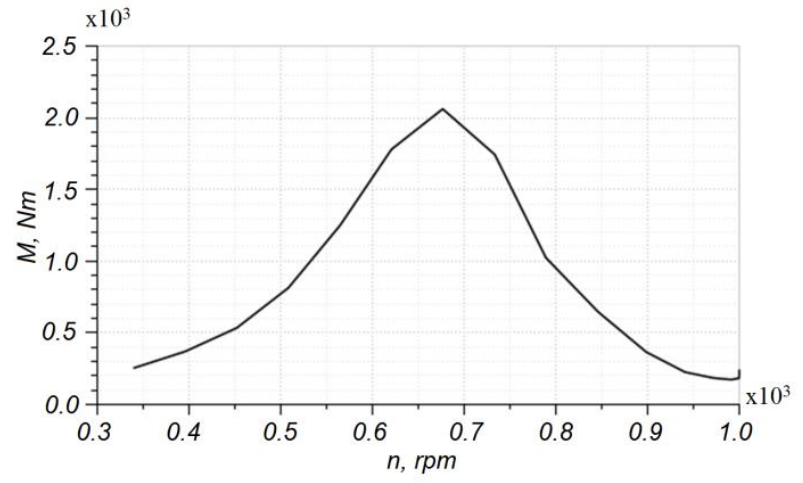

$\mathrm{k}$



1

Fig. 4. The results of simulation to assess the effectiveness of introducing the element "dry friction" in the design of the torsion oscillation damper at different intensity of passing through the resonance zone during engine start-up: a, c, e, g, i, $\mathrm{k}$ - torsion damper without dissipation; $\mathrm{b}, \mathrm{d}, \mathrm{f}, \mathrm{h}, \mathrm{j}, \mathrm{l}$ - damper with dissipation (dry friction $M_{\text {fric }}=0.33 \mathrm{kNm}, M_{t p t}=$ $0.35 \mathrm{kNm}$ ); a, b, c, d - intensity of passing through the resonance zone $6 \mathrm{rad} / \mathrm{s}^{2}$; e, f, g, h - intensity of passing through the resonance zone $50 \mathrm{rad} / \mathrm{s}^{2} ; \mathrm{i}, \mathrm{j}, \mathrm{k}, 1$ - intensity of passing through the resonance zone $100 \mathrm{rad} / \mathrm{s}^{2}$.

The findings of the computational experiment performed for the mechanical system under study show that the decrease in the dynamic torque can be even more significant than that given in [1]. It happens due to lower values of the resonance frequency and the order of the engine harmonics (resonance frequency $26 \ldots 28 \mathrm{~Hz}$ instead of $52 \ldots 56 \mathrm{~Hz}$ and the third engine harmonic instead of the sixth).

Thus, the findings suggest that the main way to reduce mechanical system dynamic loading at start-up the engine with a modern fuel control system is a substantiated adjustment of the control system operation algorithm in the "start-up" mode, which ensures fast boosting acceleration when passing through a dangerous resonance zone. At the same time, the introduction of the "dry friction" element into the design of the damper leads to a significant decrease in the dynamic torque while passing through the resonance zone. But at values of the resonance amplitudes of the torque which are smaller than the torque sum of the pretension and friction of the friction clutch, the filtering properties of the torsional oscillation damper (as a low-frequency filter) are significantly reduced. This can lead to excitation of resonance oscillations in the transmission at higher frequencies. In this regard, selection of parameters of the dissipative characteristics ("dry friction") for such a dynamic system requires additional research and taking into account its features. In this case, resonances can occur at Eigen frequencies and with higher order forms.

\section{Conclusions}

4.1 One of the possible ways to reduce mechanical system dynamic loading at starting-up the engine with a modern fuel control system is a substantiated adjustment of the control system algorithm in the "start-up" mode, which ensures fast boosting acceleration when passing through a dangerous resonance zone.

4.2 Reduction of the dynamic loading of the energypower unit at engine start-up can be achieved by introducing a damping device into the engineering design, for example, in the form of a friction-type clutch located between the flywheel and the pump impeller of the torque converter. The required effect can also be achieved by shifting the resonance frequency to the values $\left.\begin{array}{lllllll}23 & \ldots & 24 \mathrm{~Hz} & (450 & \ldots & 460 & \mathrm{rpm}\end{array}\right)$. This can be achieved by reducing the diameter of the torsion shaft when excluding "data collision ".

4.3 Taking into account that engine start-up requires significant power input to actuate the energy-power unit and other power consumers, it seems advisable to disconnect them during the start-up period. In this case, it is necessary to take into account a mechanical system natural frequency increase and, accordingly, a danger of natural frequency displacement into the engine idle speed zone.

The scientific work is carried out under the Presidential Program for Young Scientists - (Grant MK-5809.2018.8), as well as with partial funding in the framework of the state assignment of IMASH of UB RAS No. 0391 - 2014 - 007

\section{References}

1. F. De Lillo, F. Cecconi, G. Lacorata, A. Vulpiani, EPL, 84 (2008) Reik, W.; Albers, A.; Schnurr, M. u.a. Torque Control Isolation (TCI) The Smart Clutch. LuK-Symposium 1990.

2. A. Albers, Das Zweimasseznschwungrad der dritten Generation - Optimierung der Komforteigenschaften von PKW-Antriebssträngen. Antriebstechnisches Kolloquium 91, Verlag TÜV-Rheinland, 1991.

3. A. Taratorkin Dynamic Loading Reduction of Multiplate Clutches Lined Plates of the Vehicle Powertrain. SAE Technical Papers. SAE, 2014. №2014-01-2332, pp. 1 - 5 .

4. A.I. Taratorkin, [Reducing the Dynamic Load of Friction Clutches of Hydro Mechanical Transmissions of Transport Vehicles]. Trudy NAMI: sb. Nauch. St. Proceedings of NAMI: Sat. sci. art. Moscow: Nauka, 2015, Vol. 260, pp. 178 189. (in Russ.)

5. A. Albers, Simultaneous Engineering an einem Beispiel aus der KFZ-Zulieferindustrie. 
Führungskräfte-Treffen 93 des VDI-EKV Verein deutscher Ingerieure, Düsseldorf 1993.

6. A. Fidlin, R. Seebacher. DMF Simulati on Techniques. 8th LuK Symposium, 2006

7. W. Reik, A. Fidlin, R. Seebacher Good Vibrations Bad Vibrations. VDI Conference Vibrations in Drives, 2009

8. A. Kooy, A.Gillmann, J.bJäckel, M. Bosse, DMF Nothing New. 7th LuK Symposium, 2002

9. J. Kroll, A. Kooy, R. Seebacher Torsion sschwingungsdempfung fur zukunftige Motoren. Schaeffler Kolloqu. Schaeffler Technologies, Herzogenaurach 2010.

10. J. Freitag, M. Haessler, S. Lehmann, C. Raber, M. Schneider, C. Wittmann. The Clutch Comfort Portfolio: From a supplier's product to an equipment criterion. 10th Schaeffler Symposium, 2014.

11. G.S. Beloutov [Mathematical Model for Calculating the Dynamic Loads in the Input Transmission Elements During the Passage of the Resonance Zone at Engine Starting]. Aktualnye problem zashchity I bezopasnosti: Trudy XVII Vserossijskoj nauchno prakticheskoj konferencii RARAN (1-4 aprelya 2014 g.). [Edition FBGU "Russian Academy of Missile and Artillery Sciences, Moscow], 2014, pp. 142 - 149. (in Russ.)

12. V.P. Terskikh [Torsional Oscillations of the Power Shaft of the Power Plants]. Leningrad: Shipbuilding, 1970. (in Russ.)

13. S.E. Burtsev [Calculation of Dangerous Modes of Forced Oscillations of Torsional Caterpillar Systems]. Moscow, Publ. House of the Military Academy of Armored Forces, 1967. (in Russ.)

14. V.L. Veits, A.E. Kochura [The Dynamics of Machine Units with Internal Combustion Engines]. Leningrad, Mechanical Engineering, 1976. (in Russ.)

15. A.I. Grishkevich [Design of Transmissions of the Car]. Moscow, Mechanical Engineering, 1983. p. 263. (in Russ.)

16. V.B. Algin [Dynamics of Multimass Systems of Machines with Changing States of Friction Components and Directions of Power Flows]. Mechanics of machines, mechanisms and materials. 2014. no. 4 (29). pp. 21-32. (in Russ.)

17. L. Richard [Digital Signal Processing]. Translation from English. Leningrad, [Richard. 2-nd edition], Moscow, OOO «Binom-Press» Publ., 2007. (in Russ.)

18. PowerGraph [User Guide], URL: http://www.powergraph.ru (in Russ.)

19. D.Yu. Izmailov D.Yu. [PowerGraph. Part 2 Carrying out measurements of PiCAD]. Moscow: Publ. MGU, 2008, No. 2, pp. 42-46. (in Russ.)

20. [Control systems for diesel engines]. Translation from German. C40. [The first Russian edition]. Moscow, JSC «BPH» Driving», 2004. - 480 p. (in Russ.)
21. LMS Imagine.Lab Model-oriented approach to designing mechatronic systems. URL: https://www.plm.automation.siemens.com/ru_ru/pro ducts/lms/imagine-lab/amesim 